\title{
A single polypyrimidine tract binding protein (PTB) binding site mediates splicing inhibition at mouse IgM exons $M 1$ and $M 2$
}

\author{
HAIHONG SHEN, ${ }^{1}$ JULIE L.C. KAN, ${ }^{1}$ CLAUDIA GHIGNA, ${ }^{2}$ GIUSEPPE BIAMONTI, ${ }^{2}$ and MICHAEL R. GREEN ${ }^{1}$ \\ ${ }^{1}$ Howard Hughes Medical Institute, Programs in Gene Function and Expression and Molecular Medicine, University of Massachusetts Medical \\ School, Worcester, Massachusetts 01605, USA \\ ${ }^{2}$ Istituto di Genetica Molecolare, Consiglio Nazionale delle Ricerche, 27100 Pavia, Italy
}

\begin{abstract}
Splicing of mouse immunoglobulin (IgM) exons M1 and M2 is directed by two juxtaposed regulatory elements, an enhancer and an inhibitor, located within the M2 exon. A primary function of the enhancer is to counteract the inhibitor, allowing splicing to occur. Here we show that the inhibitor contains two binding sites for polypyrimidine tract binding protein (PTB). Mutational analysis indicates that only one of these sites is necessary and sufficient to direct splicing inhibition both in vitro and in vivo. We demonstrate that the difference in activity of the two sites is explained by proximity to the intron. We further show that the presence of the enhancer results in the disruption of the PTB-inhibitor interaction, enabling splicing to occur. In the absence of the enhancer, splicing can be artificially activated by immuno-inhibition of PTB. Collectively, our results indicate that a single РTB binding site can function as an inhibitor that regulates alternative splicing both in vitro and in vivo.
\end{abstract}

Keywords: pre-mRNA splicing; splicing enhancer; splicing inhibitor; polypyrimidine tract binding protein; PTB

\section{INTRODUCTION}

In eukaryotes, gene expression is controlled at both the transcriptional and post-transcriptional levels. An important form of post-transcriptional control is alternative splicing, which allows the generation of different proteins from a single gene. Alternative splicing can occur constitutively or can be regulated, for example, in a cell type or developmental specific fashion. It has been estimated that $40 \%-$ $60 \%$ of all human genes undergo alternative splicing (Modrek and Lee 2002).

The control of alternative splicing is mediated by the binding of trans-acting protein factors to cis-acting sequences within the pre-mRNA leading to differential use of splice sites. Cis-acting elements involved in alternative splice site recognition include splicing signals, such as the $5^{\prime}$ and $3^{\prime}$ splice sites and the branchpoint, as well as separate positive or negative regulatory elements. The best-characterized

Reprint requests to: Michael R. Green, Howard Hughes Medical Institute, Programs in Gene Function and Expression and Molecular Medicine, University of Massachusetts Medical School, 364 Plantation Street, Worcester, MA 01605, USA; e-mail: michael.green@umassmed.edu; fax: (508) 856-5473.

Article and publication are at http://www.rnajournal.org/cgi/doi/ 10.1261/rna.5229704. regulatory elements are splicing enhancers, which are typically purine-rich sequences located in exons (for review, see Blencowe 2000; Bilbao and Valcarcel 2003). A variety of RNA binding and in vitro genetic selection experiments have shown that splicing enhancers function by providing binding sites for serine-arginine (SR) proteins, a highly conserved family of splicing factors that are present throughout metazoans (Graveley 2000).

Splicing inhibitors (or silencers) are a class of negative regulatory elements. The splicing inhibitors identified to date appear remarkably diverse (Nemeroff et al. 1992; Siebel et al. 1992; Amendt et al. 1995; Del Gatto and Breathnach 1995; Staffa and Cochrane 1995; Staffa et al. 1997; Valcarcel and Gebauer 1997; Grabowski 1998; Zheng et al. 1998; Kan and Green 1999; Chou et al. 2000; Le Guiner et al. 2001; Wagner and Garcia-Blanco 2001). Several proteins with the ability to inhibit splicing have been identified, including two heterogeneous nuclear ribonucleoproteins (hnRNPs), hnRNP Al and polypyrimidine tract binding protein (PTB or hnRNP I). The hnRNP A1 protein can antagonize the function of SR proteins in certain types of alternative splicing (Mayeda and Krainer 1992; Mayeda et al. 1993; Caceres et al. 1994). PTB is a widely expressed $57-\mathrm{kDa}$ hnRNP that contains four RNA recognition motifs and binds to pyrimidine-rich elements (for review, see Valcarcel and Gebauer 
1997; Wagner and Garcia-Blanco 2001), which are often located in the 3' splice site region. Studies using RNA interference (Wagner and Garcia-Blanco 2002) and dominant-negative mutants (Charlet et al. 2002) have confirmed that PTB can repress splicing in vivo. PTB has been implicated in the regulation of tissue-specific alternative splicing of several genes, including $\alpha$ - and $\beta$-tropomyosin (Mulligan et al. 1992; Singh et al. 1995; Perez et al. 1997; Gooding et al. 1998), fibronectin (Norton 1994), c-src (Chan and Black 1997; Chou et al. 2000), GABA $A$ receptor $\gamma 2$ (Ashiya and Grabowski 1997), and $\alpha$-actinin (Southby et al. 1999).

We have been using the mouse immunoglobulin (IgM) exon enhancer substrate as a model system to study alternative splicing (Kan and Green 1999). We have shown that splicing of IgM exons M1 and M2 is directed by two juxtaposed regulatory elements, an enhancer and an inhibitor, located within the M2 exon. A primary function of the enhancer is to counteract the inhibitor, enabling splicing to occur. The IgM M2 splicing inhibitor is evolutionarily conserved; can inhibit the activity of an unrelated, constitutively spliced pre-mRNA; and acts by repressing splicing complex assembly. Here we determine the basis for the activity of the IgM M2 inhibitor.

\section{RESULTS AND DISCUSSION}

\section{Binding of PTB to the IgM M2 splicing inhibitor and disruption by the enhancer}

We have previously shown that the IgM1-2 pre-mRNA contains an $\sim 70$-nt inhibitor region at the $3^{\prime}$ end of exon 2 (Kan and Green 1999). Detailed inspection of this region revealed two potential PTB binding sites (Fig. 1A). To determine whether PTB binds to this region, we analyzed a series of IgM1-2 pre-mRNA derivatives using an ultraviolet (UV) light cross-linking assay that detects protein-RNA interactions. A uniformly ${ }^{32} \mathrm{P}$-labeled RNA substrate was incubated in nuclear extract in the presence or absence of ATP, and the reaction mixture was irradiated with UV light to induce RNA-protein cross-links. Following RNase A treatment and immunoprecipitation with an anti-PTB antibody, ${ }^{32} \mathrm{P}$-tagged polypeptides were fractionated by SDSpolyacrylamide gel electrophoresis and detected by autoradiography. Four RNA substrates were analyzed: the intact IgM1-2 pre-mRNA (IgM1-2), an IgM1-2 pre-mRNA derivative lacking the enhancer $(\operatorname{IgM} \Delta \mathrm{E})$, an RNA containing only the inhibitor (IgM-I), and a nonspecific RNA control.

Figure $1 \mathrm{~B}$ shows that in the absence of ATP, PTB was bound to all three inhibitor-containing RNA substrates but not to the nonspecific RNA. In the presence of ATP, the interaction between PTB and the IgM1-2 pre-mRNA, which contains the enhancer and undergoes splicing, was disrupted. In contrast, PTB remained bound to IgM-I and the $\operatorname{IgM} \Delta \mathrm{E}$ pre-mRNA substrate, which lack the enhancer

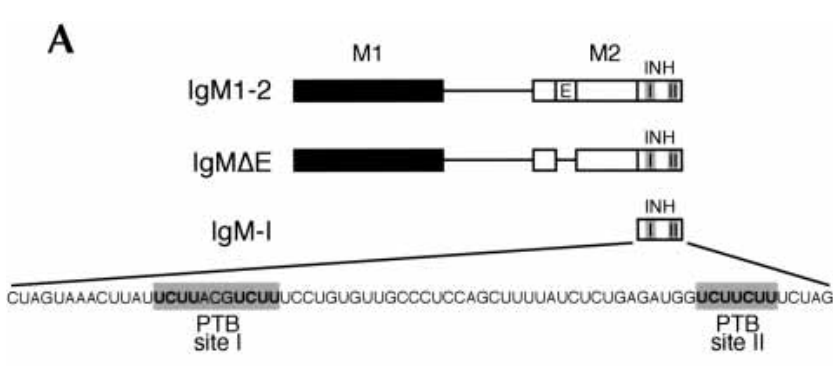

B

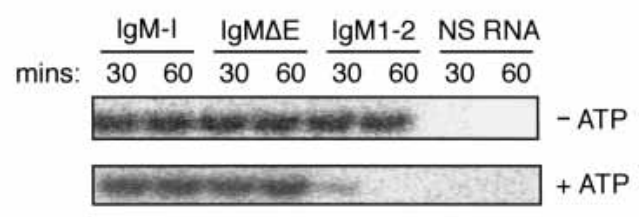

C

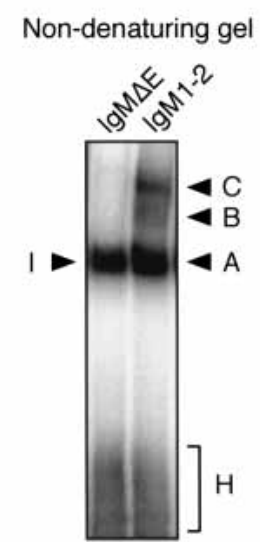

FIGURE 1. Binding of PTB to the IgM M2 splicing inhibitor and disruption by the enhancer. (A) Schematic diagrams of the IgM1-2 pre-mRNA substrate and deletion derivatives lacking the enhancer $(\operatorname{IgM} \Delta \mathrm{E})$ or containing only the inhibitor (IgM-I). M1 and M2, exons M1 and M2, respectively; E, enhancer; INH, inhibitor; I and II, PTB binding sites I and II, respectively. (B) PTB was analyzed for its ability to bind IgM1-2, IgM $\Delta \mathrm{E}$, IgM-I or a non-specific RNA control (NS RNA) using a UV cross-linking assay. HeLa nuclear extract was incubated with a uniformly ${ }^{32} \mathrm{P}$-labeled pre-mRNA substrate for 30 or 60 min in the presence or absence of ATP as indicated. (C) Splicing complexes formed on $\operatorname{IgM} \Delta \mathrm{E}$ and $\operatorname{IgM} 1-2$ were fractionated on a nondenaturing gel (left), and analyzed for PTB binding using the UV cross-linking assay (right). The PTB-pre-mRNA interaction was analyzed in the inhibitor complex (complex I), prespliceosome (complex A), mature spliceosome (complex B, C), or nonspecific $\mathrm{H}$ complex.

and do not undergo splicing. Collectively, these results indicate that PTB binds to the inhibitor and that this interaction is disrupted in the presence of the enhancer under conditions that support splicing.

To further investigate the enhancer-mediated disruption of PTB binding, we analyzed splicing complex assembly. Splicing complexes were fractionated on a nondenaturing gel (Fig. 1C, left) and analyzed for PTB binding using the UV cross-linking assay (Fig. 1C, right). The cross-linking results show that the nonspecific $\mathrm{H}$ complex contains bound $\mathrm{PTB}$, whereas the functional splicing complexes (Fig. 1A,B,C) do not. We have previously found that in the 
absence of the enhancer, an RNA substrate containing the IgM1-2 inhibitor will form a distinct inhibitor complex (complex I; Kan and Green 1999). Figure 1C shows that complex I, formed on the $\operatorname{IgM} \Delta \mathrm{E}$ pre-mRNA substrate, contains bound PTB. In conjunction with the data of Figure $1 \mathrm{~B}$, these results suggest that disruption of the $\mathrm{PTB}$-inhibitor interaction is a step involved in IgM1-2 splicing.

\section{Binding of PTB mediates splicing inhibition on IgM1-2 pre-mRNA}

We next asked whether PTB binding is required for splicing inhibition. To examine this possibility, we immuno-inhibited the function of PTB and analyzed the effect on splicing activity. Figure 2A shows that addition of an anti-PTB antibody artificially activated splicing of the $\operatorname{IgM} \Delta \mathrm{E}$ premRNA substrate, which lacks the enhancer and is otherwise unable to splice. As expected, addition of recombinant PTB to the immuno-inhibited nuclear extract restored splicing inhibition.

MS2-RS domain fusion-proteins can support enhancer activity on modified RNA substrates containing an MS2 binding site in place of the enhancer (Graveley and Maniatis 1998). Figure 2B shows that on such a modified IgM-MS2 pre-mRNA substrate, addition of either the MS2-RS fusionprotein or the anti-PTB antibody enabled splicing to occur.

In addition to the MS2-RS fusion-protein, at least one SR protein is required for splicing MS2-containing RNA substrates (Graveley and Maniatis 1998). Accordingly, Figure $2 \mathrm{C}$ shows that the IgM-MS2 substrate was spliced in an S100 extract following addition of both an MS2-RS fusionprotein and the SR protein, ASF. Splicing could also be activated in the absence of an MS2-RS fusion-protein by addition of both the anti-PTB antibody and ASF. By contrast, in the absence of ASF, addition of the anti-PTB antibody and an MS2-RS fusion-protein failed to activate splicing. Thus, immuno-inhibition of PTB can compensate for the enhancer but not the function provided by the SR protein. Collectively, the results of Figure 2 indicate that PTB mediates splicing inhibition, and that this inhibition is specifically antagonized by an enhancer-bound RS domain.
A

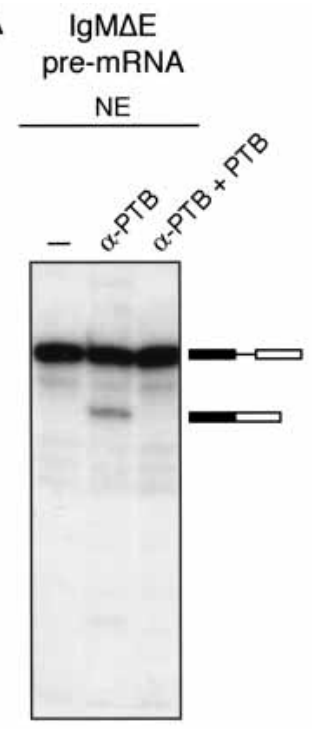

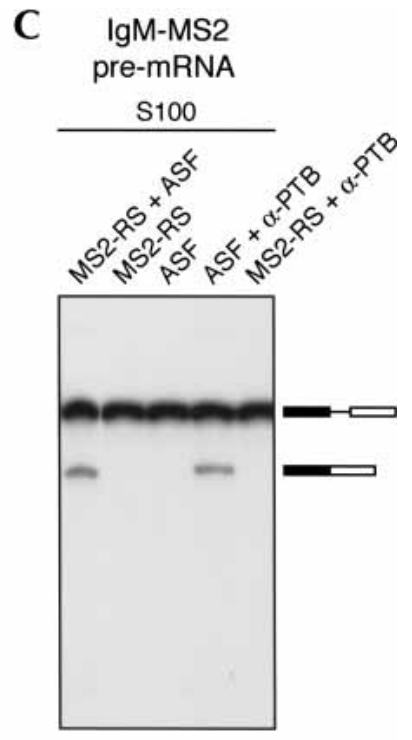

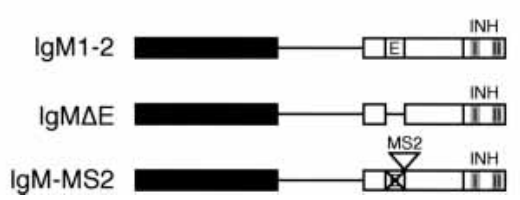

FIGURE 2. Binding of PTB mediates splicing inhibition on IgM1-2 pre-mRNA. (A) In vitro splicing of the IgM $\Delta \mathrm{E}$ pre-mRNA substrate in nuclear extract (NE) following addition of an anti-PTB antibody, or addition of recombinant PTB to the immuno-inhibited extract. $(B)$ In vitro splicing of the IgM-MS2 pre-mRNA substrate in nuclear extract following addition of an MS2-RS domain fusion-protein, MS2 alone, or MS2 plus the anti-PTB antibody. (C) In vitro splicing of the IgM-MS2 pre-mRNA substrate in S100 extract following addition of an MS2-RS domain fusion-protein, the serine-arginine protein ASF, or the anti-PTB antibody, as indicated. Schematic diagrams of the $\operatorname{IgM} 1-2, \operatorname{IgM} \Delta \mathrm{E}$ and $\operatorname{IgM}-\mathrm{MS} 2$ pre-mRNA substrates are shown.

\section{A single PTB binding site mediates splicing inhibition in vitro}

As stated above, inspection of the IgM M2 inhibitor region revealed two potential PTB binding sites. To determine the role of each of these sites in splicing inhibition, we engineered mutations in the two sites, either individually or in combination. The mutants were then analyzed in the context of either the minimal inhibitor (IgM-I) or the enhancer deletion mutant $(\operatorname{IgM} \Delta \mathrm{E})$ pre-mRNA substrate. The UV cross-linking assay of Figure $3 \mathrm{~A}$ shows that mutations in either site I or site II reduced PTB binding approximately $50 \%$, whereas the site I-II double mutant abolished PTB binding. Thus, both site I and site II are, indeed, functional PTB binding sites.

We next asked whether the site I and site II mutations would affect splicing activity in vitro. Figure $3 \mathrm{~B}$ shows that the site I mutant and the site I-II double-mutant relieved splicing inhibition of the IgM $\Delta \mathrm{E}$ pre-mRNA substrate. Unexpectedly, however, the PTB binding site II mutation had no detectable effect. These results suggest that binding of PTB to site I is necessary and sufficient for splicing inhibition in vitro.

To verify this conclusion, we tested whether site I or site II could inhibit splicing of a heterologous pre-mRNA. 
A

\section{UV crosslinking}

$\lg M-1$
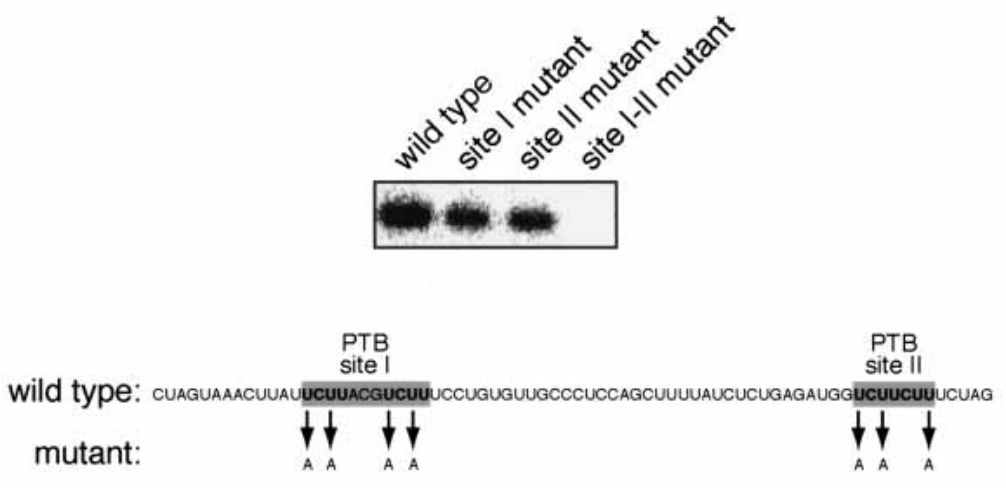

B

Splicing

$\lg \mathrm{M} \Delta \mathrm{E}$ pre-mRNA

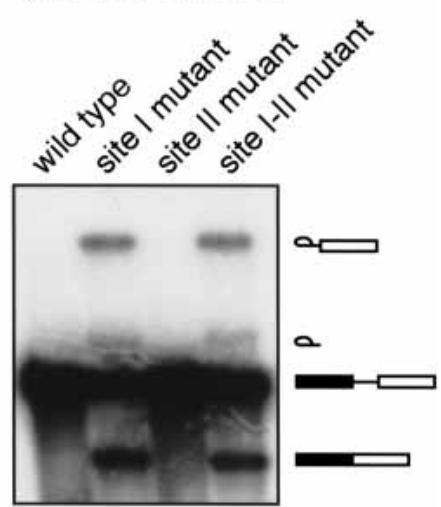

C

C Ad ML pre-mRNA
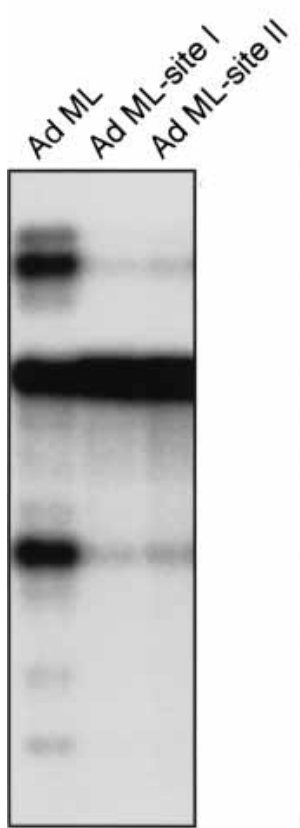

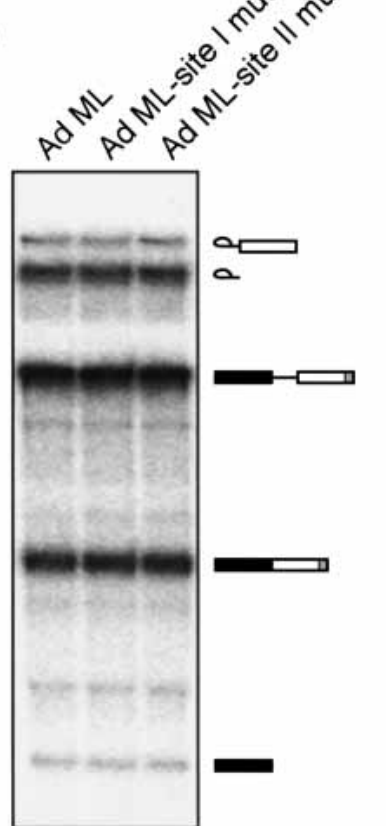

D IgM $\Delta E$ pre-mRNA
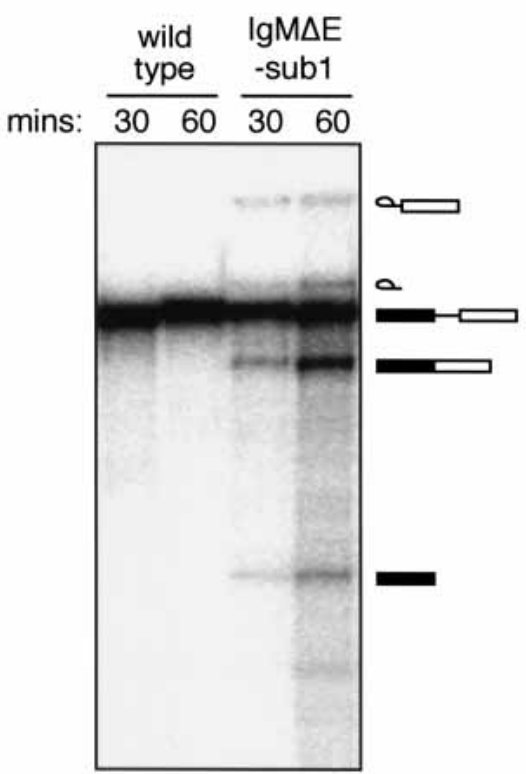

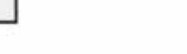

wite

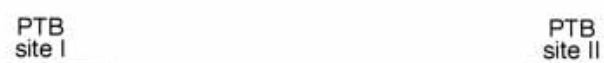

IgM $\Delta \mathrm{E}$-sub1:

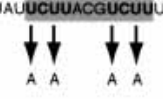

site II

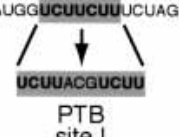

FIGURE 3. A single PTB binding site mediates splicing inhibition in vitro. (A) Mutant derivatives of the IgM-I RNA, in which either or both of the PTB binding sites were mutated, were analyzed for their ability to bind PTB in vitro using an ultraviolet (UV) cross-linking assay. (B) PTB binding site mutant derivatives of the $\operatorname{IgM} \Delta \mathrm{E}$ pre-mRNA substrate were analyzed using an in vitro splicing assay. The sequence of the IgM M2 inhibitor showing the putative PTB binding sites and the mutant versions is shown. $(C)$ Adenovirus major late (Ad ML) pre-mRNA derivatives containing either site I or site II inserted into exon 2 were analyzed using an in vitro splicing assay. $(D)$ An IgM $\Delta \mathrm{E}$ derivative in which site I was mutated and site II was replaced with the site I sequence (IgM $\Delta \mathrm{E}$-sub1) was analyzed using an in vitro splicing assay. The sequence of the inhibitor in the wild type and IgM $\Delta$ E-subl pre-mRNA substrates is shown.

We constructed adenovirus major late (Ad ML) pre-mRNA derivatives containing either site I or site II inserted into exon 2. The splicing results of Figure 3C show that site I and, unexpectedly, site II substantially inhibited Ad ML
pre-mRNA splicing (left panel). In contrast, a site I or site II mutant had no effect on splicing of the Ad ML premRNA (right panel). Thus, a single PTB binding site is sufficient to mediate splicing inhibition. 
The results of Figure 3C indicate that either site I or site II can inhibit splicing of a heterologous pre-mRNA. However, site II is unable to inhibit splicing of the IgM1-2 pre-mRNA (Fig. 3B). Significantly, in IgM1-2, site I is closer to the intron than site II, raising the possibility that proximity may be the basis for the differential activity of the two PTB binding sites. To test this possibility, we constructed an IgM $\Delta \mathrm{E}$ derivative in which site I was mutated and site II was replaced with the site I sequence $(\operatorname{IgM} \Delta \mathrm{E}$ sub1). The results of Figure 3D show that relocation of site I to the position of site II significantly reduced the ability of site I to inhibit splicing. Based upon the combined results of Figure 3, C and D, we conclude that the different activity of sites I and II is the result of proximity to the intron.

\section{A single PTB binding site mediates splicing inhibition in vivo}

To determine whether the PTB binding site mutants would also affect splicing inhibition in vivo, we analyzed splicing of IgM1-2 inhibitor mutants in transfected COS7 cells. RNA was analyzed by RT-PCR using two sets of primer pairs, one of which overlapped the splicing junction and detected only spliced RNA (IgM1-5'/IgM1-2SJ), and a second that detected both spliced and unspliced transcripts (IgM1-5'/IgM1-3') and therefore served as a loading con- trol. Figure 4A shows that, as expected, deletion of the enhancer abolished splicing in vivo. Consistent with the in vitro results, mutation of site I or both sites I and II activated splicing in the absence of the enhancer, whereas mutation of site II had no effect. To rule out the possibility of additional, cryptic splicing products, we repeated the PCR analysis using a third set of primers (IgM1-5'/IgM2). Figure $4 \mathrm{~B}$ shows that additional splicing products were not detectable and confirms the conclusions obtained with the IgM15'/IgM1-2SJ primer pair. Collectively, the results of Figures 3 and 4 indicate that the IgM M2 splicing inhibitor contains two PTB sites, only one of which, site I, is required for splicing inhibition both in vitro and in vivo.

In this report, we have studied the basis by which the IgM M2 splicing inhibitor functions. We have shown that the inhibitor contains two functional PTB binding sites, only one of which is necessary and sufficient to direct splicing inhibition both in vitro and in vivo. We further show that the difference in activity of the two sites is explained by proximity to the intron. Abrogating inhibitor function by either mutation of the critical PTB binding site or by immuno-inhibition of PTB activated splicing in the absence of the enhancer. These results strongly support our previously proposed model for the regulation of IgM1-2 splicing through juxtaposed enhancer-inhibitor elements (Kan and Green 1999).
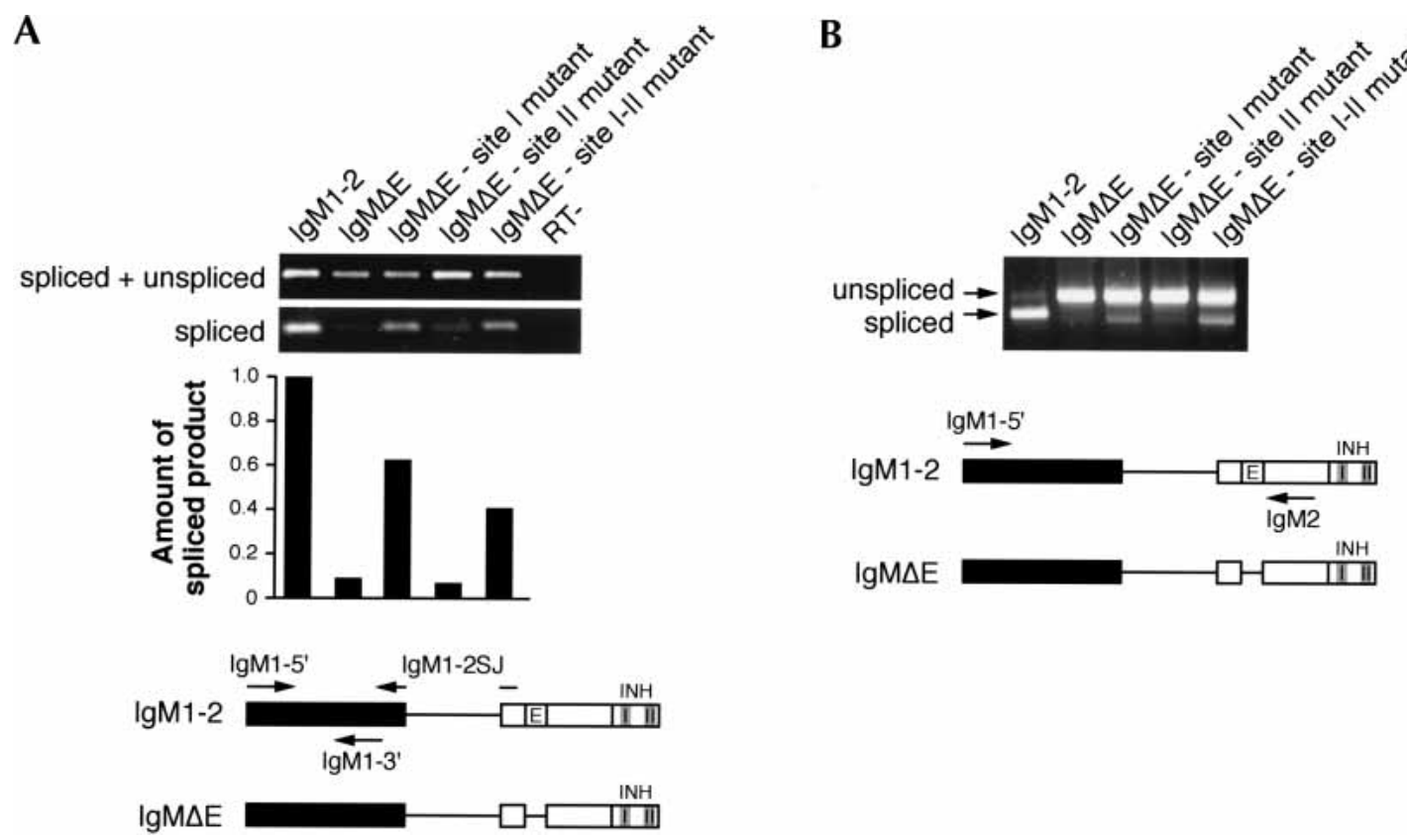

FIGURE 4. A single PTB binding protein binding site mediates splicing inhibition in vivo. IgM1-2, $\operatorname{IgM} \Delta \mathrm{E}$, and mutant derivatives of IgM $\Delta \mathrm{E}$ in which either or both of the PTB binding sites were mutated, were analyzed using an assay that monitored splicing of pre-mRNA substrates in transfected COS7 cells. (A) (Top) RNA was analyzed by RT-PCR using two sets of primer-pairs: IgM1-5' and IgM1-2SJ, which overlaps the splicing junction between the first and second exons, were used to detect spliced products; IgM1-5' and IgM1-3' were used to detect both spliced and unspliced RNAs. As a control, a reaction was also performed in the absence of reverse transcriptase (RT-). (Bottom) PCR bands were quantitated, and the ratio of spliced product to the total RNA (spliced and unspliced) was calculated and normalized to the amount of spliced IgM1-2 product. (B) RNA was analyzed by RT-PCR using the IgM1-5'/IgM2 primer-pair to investigate additional cryptic splicing products. Schematic diagrams of the IgM1-2 and IgME substrates and the location of the primers are shown. 
The basis by which PTB inhibits splicing remains to be determined, and it is likely that multiple mechanisms are involved. For example, in some cases the PTB binding site is located near the binding site for $\mathrm{U} 2 \mathrm{AF}^{65}$ (Wagner and Garcia-Blanco 2001), suggesting a simple competition mechanism. In other instances, such as the neural-specific splicing of the N1 exon of c-src pre-mRNA (Chou et al. 2000), multiple PTB binding sites, typically located in both introns flanking an exon, are required for inhibition (Wagner and Garcia-Blanco 2001). Finally, in several cases including IgM1-2, the PTB binding site or sites is located in the downstream exon (Zheng et al. 1998; Kan and Green 1999; Le Guiner et al. 2001). Whereas multiple PTB binding sites are required for inhibition of c-src pre-mRNA splicing, we have shown that for IgM1-2 a single PTB binding site is necessary and sufficient for inhibition.

We have found that the enhancer disrupts the PTB-inhibitor interaction, but the mechanism of disruption remains to be elucidated. One possibility is that the enhancer directly antagonizes the PTB-inhibitor interaction. Alternatively, the enhancer might disrupt the PTB-inhibitor interaction indirectly as a consequence of promoting splicing complex assembly. The intact IgM M2 inhibitor forms an ATP-dependent complex that contains U2 snRNA (Kan and Green 1999), which may be relevant to the mechanism of disruption. Binding of PTB to c-src pre-mRNA is disrupted in neuronal cell extracts by an ATP-dependent mechanism that does not require spliceosome assembly (Chou et al. 2000). However, as discussed above, the c-src and IgM1-2 pre-mRNAs differ with regard to important features of PTB-mediated splicing inhibition. The relative simplicity of IgM1-2 suggests it may provide an advantageous system for studying PTB-mediated splicing regulatory mechanisms.

\section{MATERIALS AND METHODS}

\section{Plasmid construction}

The IgM1-2 and IgM $\Delta \mathrm{E}$ pre-mRNA substrates were transcribed from plasmids $p \mu M 1-2$ and $p \mu M \Delta E$ (Watakabe et al. 1993). PTB site mutants were constructed in $\mathrm{p} \mu \mathrm{M} \Delta \mathrm{E}$ using a PCR-based strategy. Plasmids encoding IgM-I and PTB binding site mutant derivatives were constructed by inserting the SpeI-XbaI fragment from $\mathrm{p} \mu \mathrm{M} \Delta \mathrm{E}$ into pCRII-Topo (Invitrogen). The nonspecific RNA control was generated by T7 transcription from NdeI-linearized pSP72 (Promega). The IgM-MS2 pre-mRNA substrate was constructed by inserting the MS2 binding site into $\mathrm{p} \mu \mathrm{M} \Delta \mathrm{E}$. Plasmids encoding Ad ML-site I and Ad ML-site II were constructed by inserting annealed oligonucleotides corresponding in sequence to site I or site II into plasmid pMINX (Zillmann et al. 1988). The plasmid encoding IgM $\Delta$ E-sub1 was constructed by inserting annealed oligonucleotides corresponding to an altered inhibitor region, in which site I was mutated and site II was replaced with site I, into $\mathrm{p} \mu \mathrm{M} \Delta \mathrm{E}$. For the in vivo splicing assays, plasmids encoding the pre-mRNA substrates $\operatorname{IgM} 1-2, \operatorname{IgM} \Delta \mathrm{E}$, and $\operatorname{IgM} \Delta \mathrm{E}$-based PTB binding site mutants were constructed by inserting a blunt-ended
EcoRI-HindIII fragment from $\mathrm{p} \mu \mathrm{M} 1-2$ and $\mathrm{p} \mu \mathrm{M} \Delta \mathrm{E}$ (Watakabe et al. 1993) into the SmaI site of the pMT2 expression vector.

\section{UV cross-linking assay}

UV RNA cross-linking was performed as described previously (Wu and Green 1997). Immunoprecipitation with a rabbit polyclonal antibody raised against a C-terminal PTB peptide was performed as previously reported (Markovtsov et al. 2000).

\section{Spliceosome assembly reactions}

Spliceosome assembly reactions were performed essentially as described previously (Kan and Green 1999). Briefly, spliceosomal complexes were resolved on nondenaturing 4\% acrylamide: bisacrylamide (80:1) $-0.5 \%$ agarose gels in $50 \mathrm{mM}$ Tris base- $50 \mathrm{mM}$ glycine buffer. The gels were UV irradiated on ice using a Stratagene UV cross-linker at $2 \mathrm{~J} / \mathrm{cm}^{2}$ (Wu and Green 1997). After UV cross-linking, gel slices containing complexes from the 30-min splicing reaction were excised and incubated in $2 \mathrm{mg} / \mathrm{mL}$ RNase A solution for $30 \mathrm{~min}$ and eluted with Quik-Pik Electroelution Capsules (Stratagene) in TBE buffer for $2 \mathrm{~h}$ at $4^{\circ} \mathrm{C}$. The eluted solution was immunoprecipitated with an anti-PTB antibody as previously described (Markovtsov et al. 2000).

\section{In vitro splicing assays}

Splicing reactions were performed essentially as previously described (Kan and Green 1999). Spliced products were resolved on $12 \%$ denaturing polyacrylamide gels (19:1) in $8 \mathrm{M}$ urea in TrisBorate-EDTA buffer. For the PTB immuno-inhibition assays, 10 $\mu \mathrm{L}$ of the splicing reaction mixture (lacking pre-mRNA) was preincubated with $10 \mu \mathrm{L}$ anti-PTB monoclonal antibody BB7 for 10 min at $30^{\circ} \mathrm{C}$, followed by addition of $1 \mu \mathrm{L}$ pre-mRNA substrate. For the PTB add-back experiments, $8 \mu \mathrm{L}$ of the splicing reaction mixture (lacking pre-mRNA) was preincubated with purified recombinant His-PTB (final concentration of $2 \mu \mathrm{M}$ ) and $10 \mu \mathrm{L}$ anti-PTB monoclonal antibody $\mathrm{BB} 7$ for $10 \mathrm{~min}$ at $30^{\circ} \mathrm{C}$, followed by addition of $1 \mu \mathrm{L}$ pre-mRNA substrate. His-PTB was expressed and purified, using Ni-NTA agarose beads (Qiagen) under nondenaturing conditions, as previously described (Gooding et al. 1998; Wollerton et al. 2001). The MS2-RS fusion-protein expression plasmid was constructed in pFastBac (Invitrogen) for baculovirus production; MS2 was tagged with a His6 epitope at the N terminus and a flexible linker (GGGGGS) at the C terminus and fused in-frame to the RS domain of ASF/SF2. SF9 cells were infected with recombinant baculovirus and harvested 3-4 d postinfection, and the His-MS2-RS(ASF) fusion-protein was purified on Ni-NTA agarose beads. His-MS2-RS(ASF) and His-MS2 were added to the splicing reaction mixture at a final concentration of $1 \mu \mathrm{M}$. His-ASF was expressed using BL21 Escherichia coli cells and purified on Ni-NTA agarose beads as previously described (Caceres and Krainer 1993); the protein was added to the splicing reaction mixture at a final concentration of $2 \mu \mathrm{M}$.

\section{In vivo splicing assays}

Pre-mRNA substrate minigene constructs were transiently transfected into COS7 cells by calcium phosphate precipitation. Twenty- 
four hours after transfection, total RNA was isolated and used to generate first-strand cDNA. To determine the efficiency of splicing of minigene transcripts, equal amounts of reverse-transcribed total RNA was amplified in two separate PCR reactions using two sets of primer-pairs: IgM1-5' (5'-GAGCTGAGGAGGAAGGCTTTG$\left.3^{\prime}\right)$ and IgM1-3' (5'-CAGGGTGACGGTGGTGCTGTAGAAG-3') were used to detect both spliced and unspliced RNAs to ensure there were comparable amounts of reverse transcripts for each pre-mRNA; IgM1-5' and IgM1-2SJ (5'-TCATTTCACCTTGAA CAG-3'), which overlaps each side of the splicing junction by 9 nucleotides, were used to detect spliced RNAs. PCR bands were quantitated by densitometric analysis with NIH Image 1.3; the ratio of spliced product to the total RNA (spliced and unspliced) was calculated and normalized to the amount of spliced IgM1-2 product. To investigate additional cryptic splicing products, primer-pair IgM1-5' and IgM2 (5'-CCATCTCAGAGATAAAAG CTGGAGGGCA-3') were used.

\section{ACKNOWLEDGMENTS}

We thank Douglas Black for providing the PTB antibodies, Christopher Smith for providing the PTB protein expression vector, Adrian Krainer for providing the His-ASF expression plasmid, and Sara Evans for editorial assistance. This work was supported in part by a National Institutes of Health (NIH) grant to M.R.G. M.R.G. is an investigator of the Howard Hughes Medical Institute.

The publication costs of this article were defrayed in part by payment of page charges. This article must therefore be hereby marked "advertisement" in accordance with 18 USC section 1734 solely to indicate this fact.

Received November 7, 2003; accepted January 12, 2004.

\section{REFERENCES}

Amendt, B.A., Si, Z.H., and Stoltzfus, C.M. 1995. Presence of exon splicing silencers within human immunodeficiency virus type 1 tat exon 2 and tat-rev exon 3: Evidence for inhibition mediated by cellular factors. Mol. Cell. Biol. 15: 4606-4615.

Ashiya, M. and Grabowski, P.J. 1997. A neuron-specific splicing switch mediated by an array of pre-mRNA repressor sites: Evidence of a regulatory role for the polypyrimidine tract binding protein and a brain-specific PTB counterpart. RNA 3: 996-1015.

Bilbao, D. and Valcarcel, J. 2003. Getting to the heart of a splicing enhancer. Nat. Struct. Biol. 10: 6-7.

Blencowe, B.J. 2000. Exonic splicing enhancers: Mechanism of action, diversity and role in human genetic diseases. Trends Biochem. Sci. 25: $106-110$.

Caceres, J.F. and Krainer, A.R. 1993. Functional analysis of pre-mRNA splicing factor SF2/ASF structural domains. EMBO J. 12: 47154726.

Caceres, J.F., Stamm, S., Helfman, D.M., and Krainer, A.R. 1994. Regulation of alternative splicing in vivo by overexpression of antagonistic splicing factors. Science 265: 1706-1709.

Chan, R.C. and Black, D.L. 1997. The polypyrimidine tract binding protein binds upstream of neural cell-specific c-src exon N1 to repress the splicing of the intron downstream. Mol. Cell. Biol. 17: 4667-4676.

Charlet, B.N., Logan, P., Singh, G., and Cooper, T.A. 2002. Dynamic antagonism between ETR-3 and PTB regulates cell type-specific alternative splicing. Mol. Cell 9: 649-658.

Chou, M.Y., Underwood, J.G., Nikolic, J., Luu, M.H., and Black, D.L. 2000. Multisite RNA binding and release of polypyrimidine tract binding protein during the regulation of c-src neural-specific splicing. Mol. Cell 5: 949-957.

Del Gatto, F. and Breathnach, R. 1995. Exon and intron sequences, respectively, repress and activate splicing of a fibroblast growth factor receptor 2 alternative exon. Mol. Cell. Biol. 15: 48254834 .

Gooding, C., Roberts, G.C., and Smith, C.W. 1998. Role of an inhibitory pyrimidine element and polypyrimidine tract binding protein in repression of a regulated $\alpha$-tropomyosin exon. RNA 4: 85-100.

Grabowski, P.J. 1998. Splicing regulation in neurons: Tinkering with cell-specific control. Cell 92: 709-712.

Graveley, B.R. 2000. Sorting out the complexity of SR protein functions. RNA 6: 1197-1211.

Graveley, B.R. and Maniatis, T. 1998. Arginine/serine-rich domains of SR proteins can function as activators of pre-mRNA splicing. Mol. Cell 1: 765-771.

Kan, J.L. and Green, M.R. 1999. Pre-mRNA splicing of IgM exons M1 and $\mathrm{M} 2$ is directed by a juxtaposed splicing enhancer and inhibitor. Genes \& Dev. 13: 462-471.

Le Guiner, C., Plet, A., Galiana, D., Gesnel, M.C., Del Gatto-Konczak, F., and Breathnach, R. 2001. Polypyrimidine tract-binding protein represses splicing of a fibroblast growth factor receptor-2 gene alternative exon through exon sequences. J. Biol. Chem. 276: 43677-43687.

Markovtsov, V., Nikolic, J.M., Goldman, J.A., Turck, C.W., Chou, M.Y., and Black, D.L. 2000. Cooperative assembly of an hnRNP complex induced by a tissue-specific homolog of polypyrimidine tract binding protein. Mol. Cell. Biol. 20: 7463-7479.

Mayeda, A. and Krainer, A.R. 1992. Regulation of alternative premRNA splicing by hnRNP A1 and splicing factor SF2. Cell 68: 365-375.

Mayeda, A., Helfman, D.M., and Krainer, A.R. 1993. Modulation of exon skipping and inclusion by heterogeneous nuclear ribonucleoprotein A1 and pre-mRNA splicing factor SF2/ASF. Mol. Cell. Biol. 13: 2993-3001.

Modrek, B. and Lee, C. 2002. A genomic view of alternative splicing. Nat. Genet. 30: 13-19.

Mulligan, G.J., Guo, W., Wormsley, S., and Helfman, D.M. 1992. Polypyrimidine tract binding protein interacts with sequences involved in alternative splicing of beta-tropomyosin pre-mRNA. $J$. Biol. Chem. 267: 25480-25487.

Nemeroff, M.E., Utans, U., Kramer, A., and Krug, R.M. 1992. Identification of cis-acting intron and exon regions in influenza virus NS1 mRNA that inhibit splicing and cause the formation of aberrantly sedimenting presplicing complexes. Mol. Cell. Biol. 12: 962 970.

Norton, P.A. 1994. Polypyrimidine tract sequences direct selection of alternative branch sites and influence protein binding. Nucleic Acids Res. 22: 3854-3860.

Perez, I., Lin, C.H., McAfee, J.G., and Patton, J.G. 1997. Mutation of PTB binding sites causes misregulation of alternative $3^{\prime}$ splice site selection in vivo. RNA 3: 764-778.

Siebel, C.W., Fresco, L.D., and Rio, D.C. 1992. The mechanism of somatic inhibition of Drosophila P-element pre-mRNA splicing: Multiprotein complexes at an exon pseudo-5' splice site control U1 snRNP binding. Genes \& Dev. 6: 1386-1401.

Singh, R., Valcarcel, J., and Green, M.R. 1995. Distinct binding specificities and functions of higher eukaryotic polypyrimidine tractbinding proteins. Science 268: 1173-1176.

Southby, J., Gooding, C., and Smith, C.W. 1999. Polypyrimidine tract binding protein functions as a repressor to regulate alternative splicing of $\alpha$-actinin mutally exclusive exons. Mol. Cell. Biol. 19: 2699-2711.

Staffa, A. and Cochrane, A. 1995. Identification of positive and negative splicing regulatory elements within the terminal tat-rev exon of human immunodeficiency virus type 1. Mol. Cell. Biol. 15: $4597-4605$.

Staffa, A., Acheson, N.H., and Cochrane, A. 1997. Novel exonic elements that modulate splicing of the human fibronectin EDA exon. 
Shen et al.

\section{J. Biol. Chem. 272: 33394-33401.}

Valcarcel, J. and Gebauer, F. 1997. Post-transcriptional regulation: The dawn of PTB. Curr. Biol. 7: R705-708.

Wagner, E.J. and Garcia-Blanco, M.A. 2001. Polypyrimidine tract binding protein antagonizes exon definition. Mol. Cell. Biol. 21: 3281-3288.

Wagner, E.J. and Garcia-Blanco, M.A. 2002. RNAi-mediated PTB depletion leads to enhanced exon definition. Mol. Cell 10: 943-949.

Watakabe, A., Tanaka, K., and Shimura, Y. 1993. The role of exon sequences in splice site selection. Genes \& Dev. 7: 407-418.

Wollerton, M.C., Gooding, C., Robinson, F., Brown, E.C., Jackson, R.J., and Smith, C.W. 2001. Differential alternative splicing activity of isoforms of polypyrimidine tract binding protein (PTB). RNA 7: 819-832.

Wu, S. and Green, M.R. 1997. Identification of a human protein that recognizes the $3^{\prime}$ splice site during the second step of pre-mRNA splicing. EMBO J. 16: 4421-4432.

Zheng, Z.M., Huynen, M., and Baker, C.C. 1998. A pyrimidine-rich exonic splicing suppressor binds multiple RNA splicing factors and inhibits spliceosome assembly. Proc. Natl. Acad. Sci. 95: 1408814093.

Zillmann, M., Zapp, M.L., and Berget S.M. 1988. Gel electrophoretic isolation of splicing complexes containing U1 small nuclear ribonucleoprotein particles. Mol. Cell. Biol. 8: 814-821. 

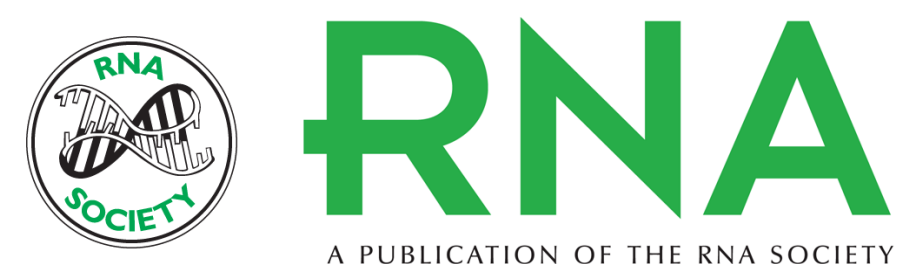

A PUBLICATION OF THE RNA SOCIETY

\section{A single polypyrimidine tract binding protein (PTB) binding site mediates splicing inhibition at mouse IgM exons M1 and M2}

HAIHONG SHEN, JULIE L.C. KAN, CLAUDIA GHIGNA, et al.

RNA 2004 10: 787-794

References This article cites 37 articles, 24 of which can be accessed free at:

http://rnajournal.cshlp.org/content/10/5/787.full.html\#ref-list-1

License

Email Alerting Receive free email alerts when new articles cite this article - sign up in the box at the Service top right corner of the article or click here.

To subscribe to $R N A$ go to:

http://rnajournal.cshlp.org/subscriptions 